Abstract

\title{
Flexible Microfabrication on a Chip during Cultivation for a Neuronal Network Direction Control Using Stepwise Photo-Thermal Etching of an Agarose Architecture ${ }^{\dagger}$
}

\author{
Yuhei Tanaka, Haruki Watanabe, Kenji Shimoda and Kenji Yasuda *
}

Citation: Tanaka, Y.; Watanabe, H.; Shimoda, K.; Yasuda, K. Flexible Microfabrication on a Chip during Cultivation for a Neuronal Network Direction Control Using Stepwise Photo-Thermal Etching of an Agarose Architecture. Eng. Proc. 2021, 4, 4. https://doi.org/10.3390/

Micromachines2021-09582

Academic Editor: Ion Stiharu

Published: 16 April 2021

Publisher's Note: MDPI stays neutral with regard to jurisdictional claims in published maps and institutional affiliations.

\section{(i)}

Copyright: (C) 2021 by the authors. Licensee MDPI, Basel, Switzerland. This article is an open access article distributed under the terms and conditions of the Creative Commons Attribution (CC BY) license (http://creativecommons.org/licenses/by/4.0/).

\author{
Department of Pure and Applied Physics, Graduate School of Advanced Science and Engineering, \\ Waseda University, Tokyo 169-8050, Japan; rmirjaa5613@fuji.waseda.jp (Y.T.); \\ watanabeharuki@akane.waseda.jp (H.W.); kenji.s@toki.waseda.jp (K.S.) \\ * Correspondence: yasuda@waseda.jp \\ + Presented at the 1st International Conference on Micromachines and Applications, 15-30 April 2021; \\ Available online: https://micromachines2021.sciforum.net/.
}

\begin{abstract}
Control over spatial distributions and patterns of individual neurons and their neurites provides an essential tool for studying the meaning of neuronal network patterns. Moreover, the complete direction control of synaptic connections between cells in each neuronal network is also essential to investigate detailed information on the relationship between the forward and feedback signaling among the cells. Here, we have developed a method for topographical control of the direction of synaptic connections within a living neuronal network using a new type of individualcell-based on-chip cell-cultivation system with an agarose microfabrication technology. The advantages of this system include the ability to control positions and number of cultured cells, as well as flexible control of the direction of elongation of axons and dendrites with stepwise melting of a thin agarose layer coated on the cultivation chip with a focused infrared laser beam even during cultivation without any destructive damage on cells. Using this system, we succeeded in forming a fully direction-controlled single-cell-based neuronal network from individual rat hippocampal cells. In this meeting, we discuss the potential damage of heat to cells during stepwise melting of agarose and demonstrate the ability of our on-chip agarose microfabrication method for individual cell-based neural networks.
\end{abstract}

Keywords: neuronal network; agarose microfabrication technology; non-destructive stepwise photo-thermal etching; neurite direction control

Supplementary Materials: The following are available online at www.mdpi.com/10.3390/Micromachines2021-09582/s1.

Institutional Review Board Statement: This study was carried out in strict accordance with the Act on Welfare and Management of Animals of the Ministry of the Environment, Japan. All animal experiments and protocols were approved by the Animal Experiment Committee of Waseda University (permission numbers: 2019-A072 and 2020-A022, respectively) and adhere to guidelines (ARRIVE 2.0) and regulations for animal experimentation.

Informed Consent Statement: Not applicable.

Data Availability Statement: Not applicable. 